\title{
Toxoplasma gondii: further studies on the subpellicular network
}

\author{
Leandro Lemgruber ${ }^{1}$, John A Kloetzel ${ }^{2}$, Wanderley de Souza ${ }^{1,3}$, Rossiane C Vommaro ${ }^{1 /+}$ \\ 'Laboratório de Ultraestrutura Celular Hertha Meyer, Centro de Ciências da Saúde, Instituto de Biofísica Carlos Chagas Filho, \\ Universidade Federal do Rio de Janeiro, Cidade Universitária Bl. G, 21941-902 Rio de Janeiro, RJ, Brasil ²Department of Biological \\ Sciences, University of Maryland Baltimore County, Baltimore, Maryland, USA ${ }^{3}$ Diretoria de Programas, Instituto Nacional de Metrologia, \\ Normalização e Qualidade Industrial-INMETRO, Rio de Janeiro, RJ, Brasil
}

The association of the pellicle with cytoskeletal elements in Toxoplasma gondii allows this parasite to maintain its mechanical integrity and makes possible its gliding motility and cell invasion. The inner membrane complex (IMC) resembles the flattened membrane sacs observed in free-living protozoa and these sacs have been found to associate with cytoskeletal proteins such as articulins. We used immunofluorescence microscopy to characterise the presence and distribution of plateins, a sub-family of articulins, in T. gondii tachyzoites. A dispersed labelling of the whole protozoan body was observed. Electron microscopy of detergent-extracted cells revealed the presence of a network of $10 \mathrm{~nm}$ filaments distributed throughout the parasite. These filaments were labelled with anti-platein antibodies. Screening the sequenced T. gondii genome, we obtained the sequence of an IMC predicted protein with $25 \%$ identity and $42 \%$ similarity to the platein isoform alpha 1 present in Euplotes aediculatus, but with $42 \%$ identity and $55 \%$ similarity to that found in Euglena gracilis, suggesting strong resemblance to articulins.

Key words: Toxoplasma gondii - cytoskeleton - articulin - platein - subpellicular network

Toxoplasma gondii is an important opportunistic pathogen that can lead to serious complications in congenitally infected newborns and in HIV-positive individuals and other immunocompromised patients (Israelski \& Remington 1993, Luft et al. 1993, Wong \& Remington 1994).

In order to survive in different challenging environments, such as the digestive tract and the circulatory system of hosts (i.e., both intra and extra-cellular milieus), T. gondii must maintain its structural integrity, a property greatly dependent upon the organism's pellicle and cytoskeletal components. The association of the plasma membrane with a system of flattened vesicles composes the pellicle. Connected with this structure, there are 22 subpellicular microtubules running down two-thirds of the parasite from its apical pole (De Souza et al. 2009). A network of interwoven filaments called the subpellicular network extends along the parasite's entire cell body (Mann \& Beckers 2001). This network is resistant to detergent extraction and is also connected to the pellicle, suggesting that it functions as a part of the membrane skeleton in $T$. gondii.

Membrane skeletons are commonly found in freeliving protozoa, maintaining the cell shape and providing mechanical stability. Examples of such cytoskeletal proteins are the tetrins, described in Tetrahymena (Honts \& Williams 1990, Brimmer \& Weber 2000), the epiplasmins, identified in Paramecium (Nahon et al. 1993, Coffe et al. 1996, Pomel et al. 2006) and other protists (Huttenlauch et al. 1998, Bouchard et al. 2001), and

\footnotetext{
Financial support: CNPq, CAPES, Pronex-Faperj

+ Corresponding author: vommaro@biof.ufrj.br

Received 17 December 2008

Accepted 2 July 2009
}

the articulins, described in the cortex of the euglenoid Euglena gracilis (Marrs \& Bouck 1992) and the ciliate Pseudomicrothorax dubius (Huttenlauch et al. 1998). Kloetzel et al. (2003) first described a sub-family of articulins, the plateins, which are the major structural components of a monolayer of flattened scales (the "alveolar plates") located within membranous sacs (cortical alveoli) in the free-living protozoon Euplotes aediculatus. As the alveolar plates of these free-living protozoa constitute a skeletal system related to that described in Apicomplexa, we decided to use specific antibodies recognising these structures to determine if articulins are found in T. gondii. Our present results suggest that components of the subpellicular network have a common nature with cytoskeletal elements of free-living protozoa.

\section{MATERIALS AND METHODS}

Indirect immunofluorescence - T. gondii RH strain tachyzoites were harvested in MTSB (4 M glycerol, 100 mM PIPES, $1 \mathrm{mM}$ EGTA, $5 \mathrm{mM} \mathrm{MgCl}$ ), $\mathrm{pH} 6.8$ and fixed in $2 \%$ paraformaldehyde in the same buffer. After fixation, the cells were rinsed in MTSB, allowed to adhere to previously poly-1-lysine-coated coverslips and permeabilised with $0.2 \%(\mathrm{v} / \mathrm{v})$ Triton X-100 for $10 \mathrm{~min}$. After washing, unspecific sites were quenched with $3 \%$ $(\mathrm{w} / \mathrm{v})$ bovine serum albumin solution for $1 \mathrm{~h}$ and the cells were incubated with undiluted primary antibody - mouse monoclonal mAB PL-5 (which recognises all platein isoforms) or 1/10 dilution of the rabbit polyclonal AP-2 (which recognises only alpha platein isoforms) (Kloetzel et al. 2003). After $1 \mathrm{~h}$ of incubation at RT, parasites were washed and incubated with the corresponding secondary antibodies (conjugated to AlexaFluor ${ }^{\circledR} 488$; Molecular Probes) at RT for $1 \mathrm{~h}$. Coverslips were observed in a Zeiss Axioplan microscope equipped with a fluorescein filter set. The images were acquired with a colour-chilled CCD camera (Hamamatsu, Japan). 
Immunoelectron microscopy of uranyl acetate stained preparations - Tachyzoites were incubated with MTSB containing $1 \%(\mathrm{v} / \mathrm{v})$ Triton X-100, 1\% (v/v) NP-40 for 20 min. Detergent-treated parasites were allowed to settle onto formvar-coated copper grids for $10 \mathrm{~min}$, blocked with $3 \%$ bovine serum albumin and incubated with $0.01 \%$ Tween 20 for $1 \mathrm{~h}$. Afterwards, grids were incubated in a humid chamber with mAB PL-5 or AP-2 at the same dilutions used for fluorescence microscopy for $1 \mathrm{~h}$. Grids were then incubated with secondary antibody conjugated to $10 \mathrm{~nm}$ gold particles (BBInternational) for $1 \mathrm{~h}$ and fixed in $2.5 \%$ glutaraldehyde. For staining, parasites were incubated for $1 \mathrm{~min}$ with $1 \%(\mathrm{v} / \mathrm{v})$ uranyl acetate. After washing in distilled water, the grids were observed in a Jeol 1,200 EX transmission electron microscope.

Sequence analysis - Predicted protein sequences were analysed using public databases at the BLAST program (http://www.ncbi.nlm.nih.gov) and the T. gondii genome project (http://toxodb.org). Peptide alignments were performed using ClustalW (European Bioinformatics Institute).

\section{RESULTS AND DISCUSSION}

Uranyl acetate negative staining of detergent-extracted tachyzoites of $T$. gondii provided a full visualisation of the cytoskeleton arrangement (Fig. 1A). The interwoven filaments of the subpellicular network, approximately $10 \mathrm{~nm}$ in diameter, extended homogeneously along the entire length of the parasite. The subpellicular microtubules, which originate from the conoid, do not reach the posterior portion of the protozoan. The thin filaments observed appeared to surround the subpellicular microtubules in the anterior region of the protozoan (Fig. 1A). They ended in a well-delimited circular structure, which ranged from 300-650 $\mathrm{nm}$ in diameter (Fig. 1A), localised at the posterior tip. This structure, recently characterised as a basal complex, contains proteins such as TgMORN1, TgCentrin 2 and a Dynein light chain (Hu 2008). Apparently, the subpellicular network provides the shape of the parasite. In daughter parasites, however, this structure is loose and yet susceptible to detergent extraction, to be expanded and remodelled during growth of the parasites (Mann et al. 2002). This unstable structure changes into the rigid and stable structure in mature parasites, as observed in our detergent extraction preparations.

Fluorescence microscopic analysis using the PL-5 antibody, which recognises all platein isoforms and AP-2, which recognises the alpha-platein isoform only, showed a dispersed labelling of the tachyzoites (Fig. 2B, D). The labelling pattern was similar to that found by Mann and Beckers (2001), using antibodies that recognise two proteins [Tg-inner membrane complex (IMC) 1 and 2] isolated from the protozoan cytoskeleton. No labelling was observed in negative controls when we omitted the primary antibodies (data not shown). The concentrations of the antibodies were the same as those used by Kloetzel et al. (2003) in E. aediculatus. Although the concentrations of antibodies were high, the labelling was specific in both EM and IF preparations. The localisation of platein-like proteins using immunoelectron microscopy of detergent-extracted samples with the same antibodies

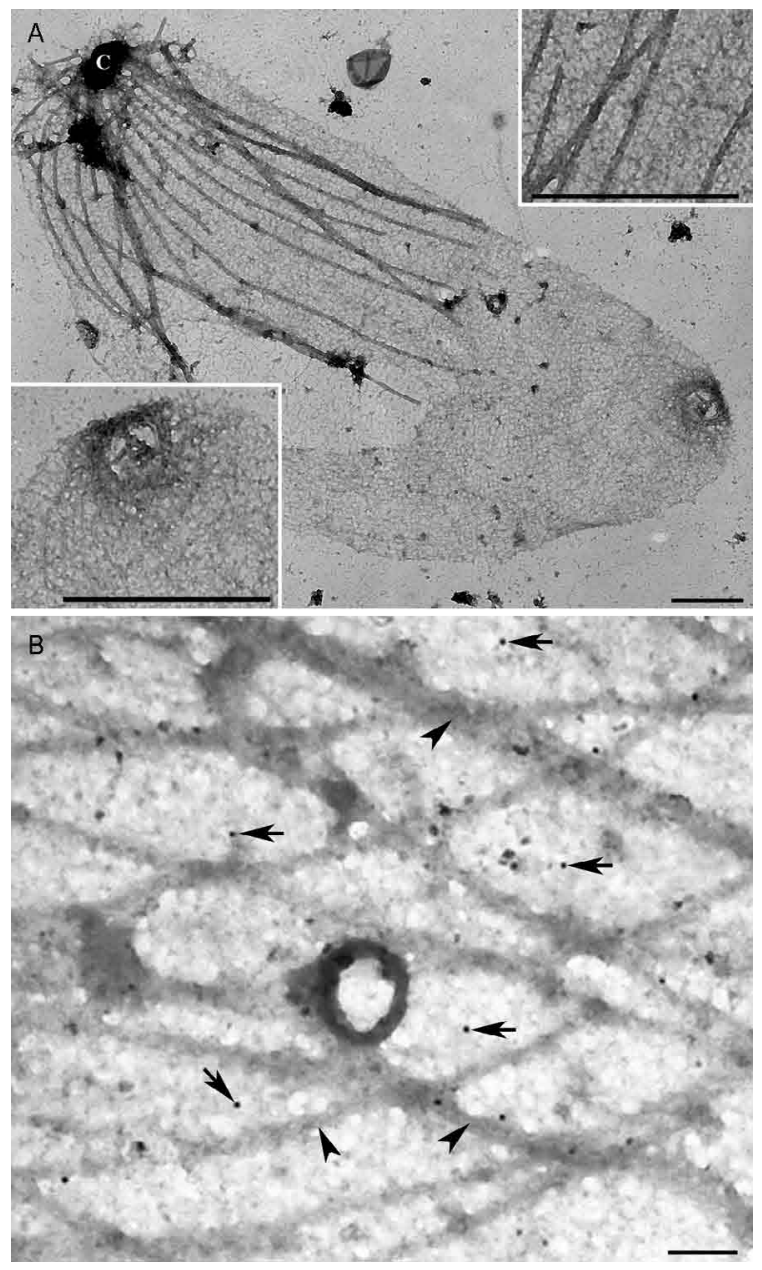

Fig. 1A: Toxoplasma gondii tachyzoite detergent-extracted sample. The subpellicular microtubules originate from the conoid (c) and do not reach the posterior part of the parasite cell body. The elements of the subpellicular network are present in the full extent, ending in an electron dense circular structure (inset). In the other inset we can compare the diameter difference between the subpelicular microtubules and the subpelicular network. Bar $=0.25 \mu \mathrm{m}$; B: immunoelectron labeling of the filaments of the subpelicullar network with the antibody AP-2 (black arrows). Arrowheads: subpellicular microtubules. Bar $=0.1 \mu \mathrm{m}$.

showed a labelling in the elements which form the subpellicular network, as can be seen in Fig. 1B. This labelling pattern also resembles that observed using antibodies recognising actin (Patron et al. 2005), indicating that both microfilaments and articulins are associated with the subpellicular network.

Plateins are N-terminal signal polypeptides (Kloetzel et al. 2003). Their canonical hydrophobic signals direct the plateins within the membrane-limited alveolar sacs, where they are assembled into plates. T. gondii subpellicular network elements do not form plates (M Attias, W De Souza 2009, unpublished observations), unlike those observed in E. aediculatus; however, these structures are in close contact with a group of flattened cisternae, the IMC that may be a specialised region of the endoplasmic reticulum (De Melo \& De Souza 1997). 

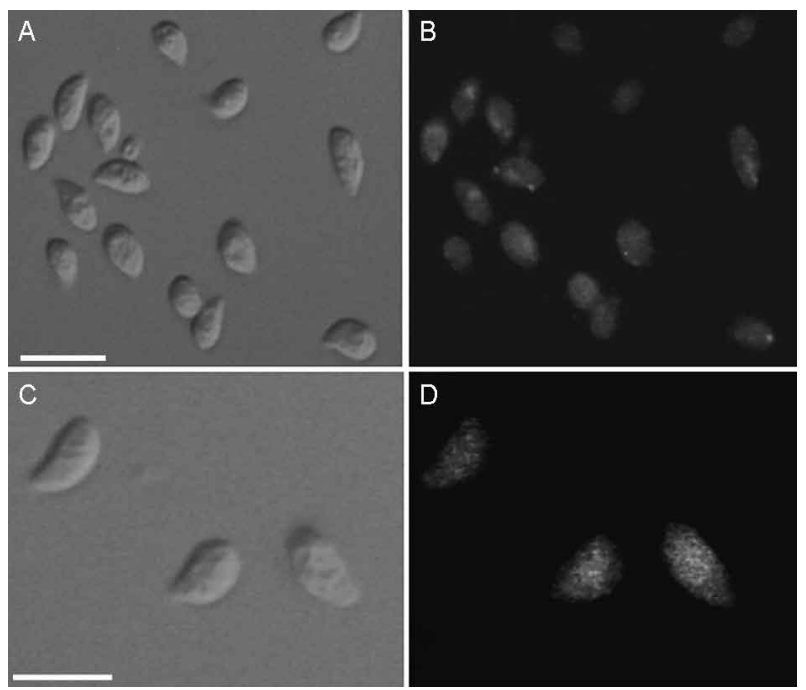

Fig. 2: observe that the full extents of Toxoplasma gondii tachyzoites cell bodies are labeled with $\mathrm{mAB}$ PL-5 (B), which recognizes all platein isoforms, and with AP-2 (D), which recognizes only alpha platein isoforms. A, C: DIC images of B and D, respectively. Bars $=8 \mu \mathrm{m}$.

In the first description of the subpellicular network, the authors proposed the interaction of this structure with subpellicular microtubules and these structures that were in contact with the cytoplasmic face of the IMC, forming the $T$. gondii membrane-skeleton (Mann $\&$ Beckers 2001). Patron et al. (2005) have proposed that the subpellicular network may also be in contact with the plasma membrane face of the IMC and may take part in the organism's gliding machinery, as T. gondii actin has been found to be associated with this structure. The subpellicular network could thus anchor Toxoplasma's cortical myosin in the IMC membrane, thereby providing mechanical support to the parasite, maintaining its shape during movement as well as during the invasion of host cells. This model is in accordance with the observations made by Khater et al. (2004) of Plasmodium sporozoites lacking the membrane skeleton protein PbIMC1, a structural orthologue of the TgIMC1. These mutant parasites demonstrated reduced motility, infectivity and resistance to osmotic shock relative to wild-type organisms. However, in our negative staining preparations, we could not establish any connection of the filaments to the IMC in T. gondii.

Using the BLAST program and the T. gondii genome resource (ToxoDB), we obtained a protein sequence (access ID 42.m03481) similar to the alpha-1 platein isoform (25\% identity and $42 \%$ similarity) (Fig. 3), predicting a function for this sequence. The same protein sequence was obtained when blasting with alpha-2 isoform. Using the beta/gamma platein isoform, we obtained another sequence; however, this sequence had low similarity and was thus not considered further. We used the program SignalP to determine whether the sequences obtained also presented an N-terminal signal sequence, a hallmark characteristic of plateins. No signal sequence was identified, however, indicating that the sequence identi-

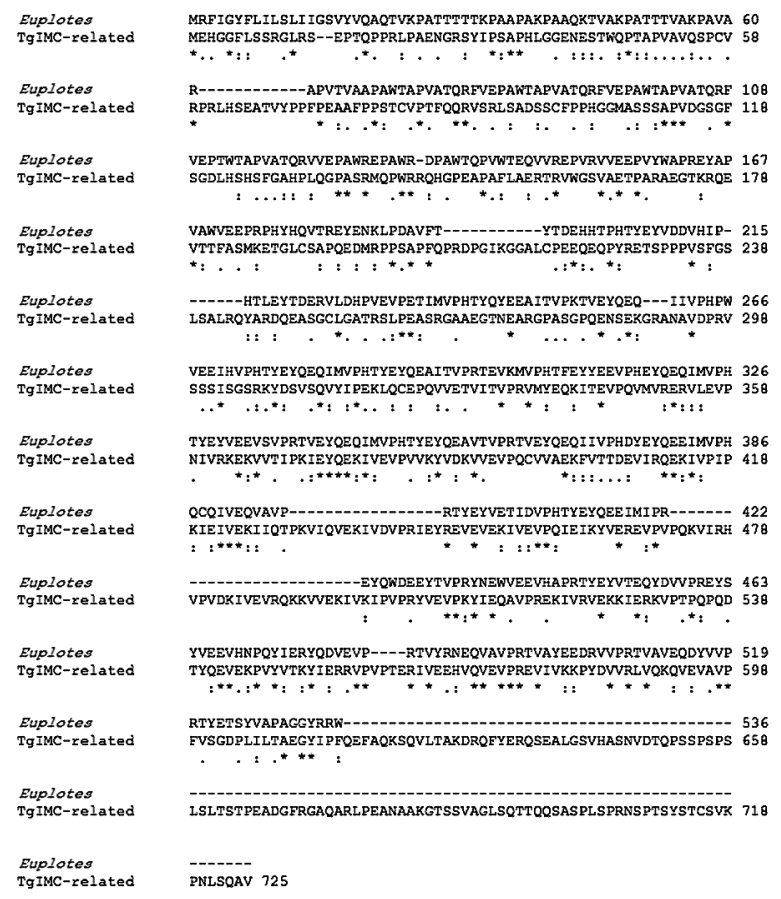

Fig. 3: alignment of the Euplotes aediculatus platein isoform alpha 1 with a Toxoplasma gondii inner membrane complex (IMC)-related predicted protein. The analysis was performed using ClustalW. Asterisks mean identical residues; points mean semi-conserved substitutions; double-points mean conserved substitutions.

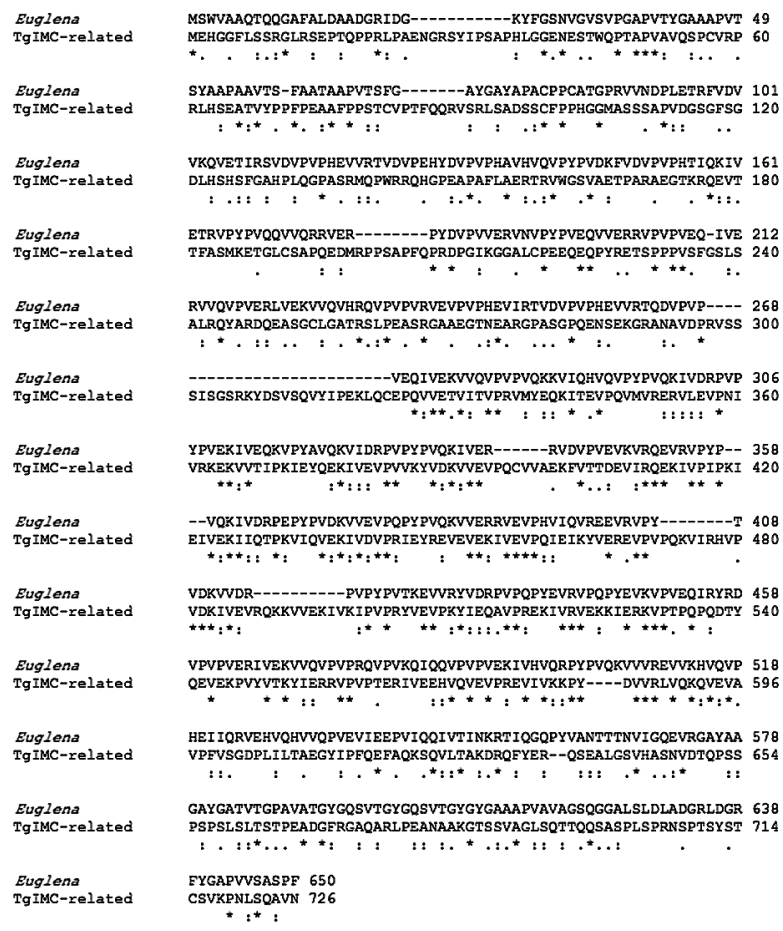

Fig. 4: alignment of the Euglena gracilis articulin with a Toxoplasma gondii inner membrane complex (IMC)-related predicted protein. The analysis was performed using ClustalW. Asterisks mean identical residues; points mean semi-conserved substitutions; double-points mean conserved substitutions. 
fied (42.m03481) did not correspond to a secreted protein and therefore it could not be considered a platein. Interestingly, the sequence obtained has $42 \%$ identity and $55 \%$ similarity with $E$. gracilis articulin, suggesting that the sequence is more closely related to articulins than plateins (Fig. 4). Since plateins are a sub-family of articulins, they share common sequences, explaining why we observed a labelling with the antibodies for platein isoforms. The blast score obtained with $E$. gracilis was higher than that obtained by Mann and Beckers (2001), comparing TgIMC1 and $E$. articulin $(37 \%$ identity and $45 \%$ similarity). This particular $T$. gondii sequence shares only a weak identity (26\%) with the TgIMC1 sequence obtained by Mann and Beckers (2001), even though the encoded proteins appear to occupy a common location within the protozoan. This suggests that we have detected an additional member of the IMC family of genes in this parasite, expressing a protein with a resemblance to articulins.

Overall, our present results, in comparison with the findings of others, led to two important conclusions. First, they support the general pattern that cytoskeletal elements in protists seem to be comprised of multiple forms of related proteins; this is exemplified by the multigenic protein family of epiplasmins observed in Paramecium (Coffe et al. 1996, Pomel et al. 2006), the multiple fibre-forming tetrins found in Tetrahymena (Brimmer \& Weber 2000, Bouchard et al. 2001) and the platein variants found together in the alveolar plates of Euplotes (Kloetzel et al. 2003). Secondly, our findings suggest that subpellicular network filaments in Toxoplasma share several common features with cytoskeletal elements of free-living protozoa. We thus infer that articulins and the IMC proteins of Apicomplexa share a common ancestry.

\section{ACKNOWLEDGEMENTS}

To Dr. André Jeovanio-Silva and Sarah Nardeli, for helpful discussions, and to Antonio Bosco, for technical support.

\section{REFERENCES}

Attias M, De Souza W 2009. A review of the Apicomplexa cytoskeleton. Trends Cell \& Mol Biol, in press.

Bouchard P, Chomilier J, Ravet V, Mornon JP, Viguès B 2001. Molecular characterization of the major membrane skeletal protein in the ciliate Tetrahymena pyriformis suggests n-plication of an early evolutionary intermediate filament protein subdomain. J Cell Sci 114: 101-110.

Brimmer A, Weber K 2000. The cDNA sequences of three tetrins, the structural proteins of the Tetrahymena oral filaments, show that they are novel cytoskeletal proteins. Protist 151: 171-180.

Coffe G, Le Caer JP, Lima O, Adoutte A 1996. Purification, in vitro reassembly and preliminary sequence analysis of epiplasmins, the major constituent of the membrane skeleton of Paramecium. Cell Mot Cytosk 34: 137-151.

De Melo EJT, De Souza W 1997. A cytochemistry study of the inner membrane complex of the pellicle of tachyzoites of Toxoplasma gondii. Parasitol Res 83: 252-256.

De Souza W, DaMatta RA, Attias M 2009. Brazilian contribution for a better knowledge on the biology of Toxoplasma gondii. Mem Inst Oswaldo Cruz 104: 149-154.

Honts JE, Williams NE 1990. Tetrins: polypeptides that form bundled filaments in Tetrahymena. J Cell Sci 96: 293-302.

$\mathrm{Hu} \mathrm{K} 2008$. Organizational changes of the daughter basal complex during the parasite replication of Toxoplasma gondii. PLoS Pathogens 4: e10.

Huttenlauch I, Peck RK, Stick R 1998. Articulins and epiplasmins: two distinct classes of cytoskeletal proteins of the membrane skeleton in protests. $J$ Cell Sci 111: 3367-3378.

Israelski DM, Remington JS 1993. Toxoplasmosis in the non-AIDS immunocompromised host. Curr Clin Top Infect Dis 13: 322-356.

Khater EI, Sinden RE, Dessens JT 2004. A malaria membrane skeletal protein is essential for normal morphogenesis, motility and infectivity of sporozoites. J Cell Biol 167: 425-432.

Kloetzel JA, Baroin-Tourancheau A, Miceli C, Barchetta S, Farmar J, Banerjee D, Fleury-Aubusson A 2003. Cytoskeletal proteins with N-terminal signal peptides: plateins in the ciliate Euplotes define a new family of articulins. J Cell Sci 116: 1291-1303.

Luft BJ, Hafner R, Korzun AH, Leport C, Antoniskis D, Bosler EM, Bourland DD, Uttamchandani R, Fuhrer J, Jacobson J, Morlat P, Vilde J, Remington JS 1993. Toxoplasmic encephalitis in patients with the acquired immunodeficiency syndrome. $N$ Eng $\mathrm{J} \mathrm{Med}$ 329: 995-1000.

Mann T, Beckers C 2001. Characterization of the subpellicular network, a filamentous membrane skeletal component in the parasite Toxoplasma gondii. Mol Biochem Parasitol 115: 257-268.

Mann T, Gaskins E, Beckers C 2002. Proteolytic processing of TgIMC1 during maturation of the membrane skeleton of Toxoplasma gondii. J Biol Chem 277: 41240-41246.

Marrs JA, Bouck GB 1992. The two major membrane skeletal proteins (articulins) of Euglena gracilis define a novel class of cytoskeletal proteins. J Cell Biol 118: 1465-1475.

Nahon P, Coffe G, Le Guyader H, Darmanaden-Delorme J, JeanmaireWolf R, Clérot JC, Adoutte A 1993. Identification of the epiplasmins, a new set of cortical proteins of the membrane cytoskeleton in Paramecium. J Cell Sci 104: 975-990.

Patron SA, Mondragon M, Gonzales S, Ambrosio JR, Guerrero BAL, Mondragon R 2005. Identification and purification of actin from the subpellicular network of Toxoplasma gondii tachyzoites. Int $J$ Parasitol 35: 883-894.

Pomel S, Diogon M, Bouchard P, Pradel L, Ravet V, Coffe G, Viguès B 2006. The membrane skeleton in Paramecium: molecular characterization of a novel epiplasmin family and preliminary GFP expression results. Protist 157: 61-75.

Wong S, Remington JS 1994. Toxoplasmosis in pregnancy. Clin Infect Dis 18: 853-862. 